\title{
Market Based Analysis of Power System Interconnections
}

\author{
Artjoms Obushevs ${ }^{1}$, Mario Turcik ${ }^{2}$, \\ Irina Oleinikova ${ }^{3},{ }^{1-3}$ Institute of Physical Energetics, Gatis Junghans, JSC "Latvenergo"
}

\begin{abstract}
Analysis in this Article is focused on usage of transmission grid under liberalized market with implicit transmission capacity allocation method, e.g. Nordic market. Attention is paid on fundamental changes in transmission utilization and its economical effective operation. For interconnection and power flow analysis and losses calculation model of Nordic grid was developed and transmission losses calculation method was created. Given approach will improve economical efficiency of system operation in electricity market conditions.
\end{abstract}

Keywords - Electricity market, HVDC technology, power flow.

\section{INTRODUCTION}

Power system analysis comprises of analyzing of internal transmission system and cross-border and cross-area interconnections and its transmission capability as well as deployment and structures of power generating units. Utilization of power system generation and transmission capacities is performed by market needs and partly for maintaining of system stability and security represented by transmission reliability margin and reserves in power generation. Power flows along inter-area connections based on market principles are driven by price differences between them. Effectiveness and optimal performance of System operation governed by market principles should take into account the merits of electricity transmission between Areas in situations when difference of prices in comparison to transmission costs is not economically effective. Losses optimization management determines optimal utilization of interconnection under conditions of electricity market and its trading rules.

\section{BALTIC AND NORDIC POWER SYSTEM ANALYSIS}

Inter-States transmission lines and its capacities were predominantly constructed to maintain stability and increase security of interconnected power systems. However, new wellfunctioning electricity market with competitive environment considerably depends on possibilities transmit power between power producers and consumers. Therefore, liberalization of electricity markets has increased importance of transmission capacity sufficiency on internal transmission lines as well as cross-border connections due the growth of trades and exchanges between countries. Benefits of involved countries flows from cross-border trade and transfer of energy across country what enhance utilization of transmission system and in many cases requires strengthening its capability.

Power systems of Baltic States (Estonia-Latvia-Lithuania) working synchronously with power systems of Belarus and
Russia. Utilization of transmission cross-border lines capacity strongly depends on internal transmission capability of respective Country. Due that reasons many projects for internal grids reinforcement were performed. Transmission grids operates at the following $\mathrm{AC}$ voltage levels: Estonia: 110/330 kV; Latvia: 110/330 kV; Lithuania: 110/330/750 kV. Power production in Baltic is centralized into several major power plants. Estonia predominantly generates electricity by oil shale-fired thermal power plants and partly by combined heat and power technology. Latvia producing electricity mostly by combined heat and power plants and hydro power plants while power production in Lithuania is based on hydro, thermal and combined heat and power units. Installed power generation capacity in Baltic by energy source is shown on Fig. 1

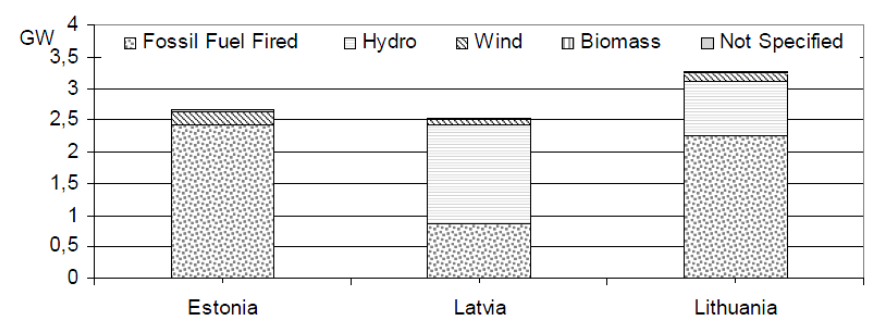

Fig. 1. Installed capacity by energy source in Baltic 2010

Diversity of power production in the Nordic leads to efforts about reinforcement on internal cross-section connection as well as about common market establishment. Common gain is increasing security and lower costs. In Norway is power generating based mostly on hydro resources. Sweden power production uses predominantly hydro and nuclear power, Finland used a mix of hydro, thermal power and nuclear. Denmark's energy supply was based almost entirely on thermal power with increasing of proportion wind. See Fig. 2.

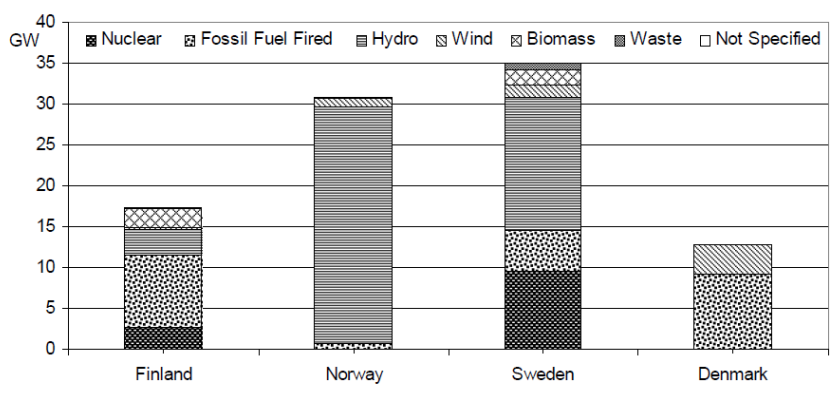

Fig. 2. Installed capacity by energy source of Nordel 2010 
Nordic grid operates at the following AC voltage levels: Denmark: 132/150/220/400 kV; Finland: 110/220/400 kV; Norway: 300/420 kV (and $132 \mathrm{kV}$ northern Norway); Sweden: 220/400 kV; The HVDC links between subsystems at 285-400 $\mathrm{kV}$. Cross-border interconnections also constitute numbers of lines on lower voltages.

The delivery capacity of the system as a whole is higher than the sum of the individual delivery capacities of the subsystems [1]. As a result of the expansion of transmission capacity between the subsystems, the interconnected Nordic electric power system operates increasingly as a single entity.

\section{HVDC INTERCONNECTIONS}

\section{A. HVDC submarine cable Fenno-Skan}

Submarine HVDC cable commissioned in 1989 which reinforced coupling of power systems of Finland and Sweden. Cable length is $200 \mathrm{~km}$. Currently owned by Fingrid (Finland) and Svenska Kraftnät (Sweden). Link is used for power exchange in both directions. Rated voltage $400 \mathrm{kV}$, presently operates as monopolar (planed bipolar extension). See Fig. 3. Transmission capacity is temperature-dependent, normally at $550 \mathrm{MW}$ with short overload possibility at the $600 \mathrm{MW}$.

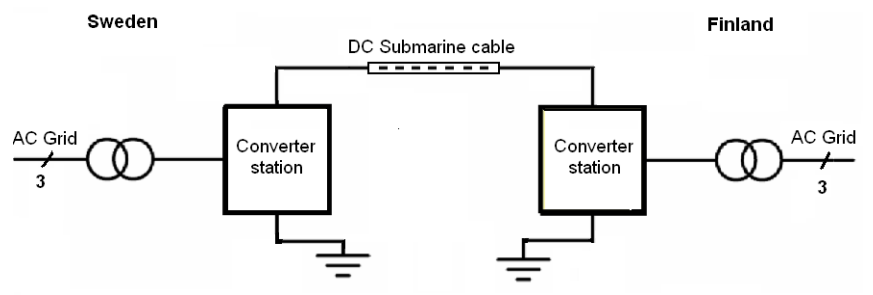

Fig. 3. Principal Fenno-Skan configuration

Main assets of interconnection are reduction of transmission distances between south-western Finland and east central Sweden, which represents areas with high concentration of consumption and generating power. Interconnection also provides possibility for power flow redistribution between 400 $\mathrm{kV}$ AC lines on north and Fenno-Skan (middle). Such operation brings total system losses reduction by up to 40 MW. Furthermore, Fenno-Skan has also been provided with damping control regulators and emergency power control features, which stabilize the power systems in such a way that the power transfer capability between northern and central Sweden can be increased by $250 \mathrm{MW}$ and in same amount also increased capability of $400 \mathrm{kV}$ northern AC lines between Sweden and Finland.

\section{Operation and capacity redistribution}

Monitoring, operation and control concerning $400 \mathrm{kV}$ AC links and Fenno-Skan in Sweden is carried out by Grid Supervisor at Network Control of SvK in Racksta and in Finland from Operation Centre of Fingrid in Helsinki. FennoSkan regulation responsibility alternates between Finnish and Swedish side every half of calendar year. Transmission capacity of all interconnections is calculated on daily basis by Operation centres in Racksta and Helsinki. Available trading capacity is obtained as total transmission capacity minus determined margin for regulation purposes. As a starting point for trading capacity distribution between northern AC lines and Fenno-Skan is used basic distribution with rules in compliance with Nordic grid operation code. Elbas (Intraday trading of Nord Pool power exchange) and supportive power trading across the border are not handled in basic distribution. During periods when a disturbance in power system occurred loss minimization is not employed. Parties involved in cooperation do not pay any compensation for loss minimization benefit, only non-notified balance power is financially settled [1]. In period 2008-2012 is planned extension of Fenno-Skan with second pole (Fenno-Skan 2) due the increases in generation capacities, above all, integration of wind park near Gävle and uprates in nuclear power plant Forsmark 3. Changes are also concerned reinforcement $400 \mathrm{kV}$ AC northern lines and modifications of substations [2].

\section{B. HVDC submarine cable Estlink I}

Efforts about increasing of HVDC interconnection capacities between Nordel and rest of continental Europe are primarily based on market interests as well as better utilization of hydroelectric power generation deployed in Nordel and predominant thermal power generation in Continent. These interests are strongly powered also by European Commission with idea to establish common EU energy market. Estlink, submarine HVDC cable linked up subsystems of Finland (Espoo substation - AC $400 \mathrm{kV}$ ) and Estonia (Harku substation - AC $330 \mathrm{kV}$ ). Link with total length 210 (2 times $105) \mathrm{km}$ was commissioned in 2006. Operational voltage level of bipolar construction is +/- $150 \mathrm{kV}$. See Fig. 4.

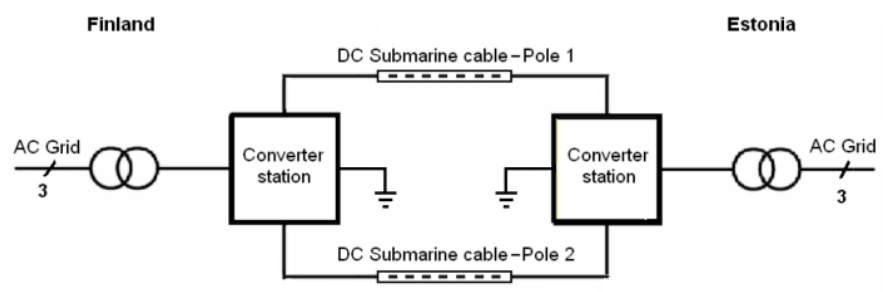

Fig. 4. Principal Estlink I configuration

Maximal transmission capacity at the 350 MW with possibility to transmit energy in either direction is primary meant for market purposes (commercial operation). Besides, interconnection improved security of supply in Baltic that creates potential channel for purchasing electricity from Nordic. Construction of cable not induced any grid improvement on Finnish side. Estimated annual import 2,5TWh from Estonia represents approximately 3\% of total current Finnish consumption. To evaluate new possible interconnections was launched multiregional study between Nordel, Baltso and PSE operator (Polish TSO) related to technical-economic impacts of new links [3].

\section{HVDC submarine cable Estlink II}

Second interconnection between Finland and Estonia will have a transmission capacity of 650 megawatts, which 
increases the total transmission capacity between the countries to 1,000 megawatts. The total length of the link is approximately $170 \mathrm{~km}$. The Estlink II connection is due to be ready in the beginning of 2014 .

\section{HVDC submarine cable NordBalt}

NordBalt (also known as SwedLit) is a planned submarine power cable between Klaipeda in Lithuania and Nybro in Sweden. The aim of the project is to promote trading between Baltic and Nordic electricity markets, as also to increase the security of power supply in both markets. The length of the cable will be $450 \mathrm{~km}$ and its capacity will be $700 \mathrm{MW}$. See Fig. 5.

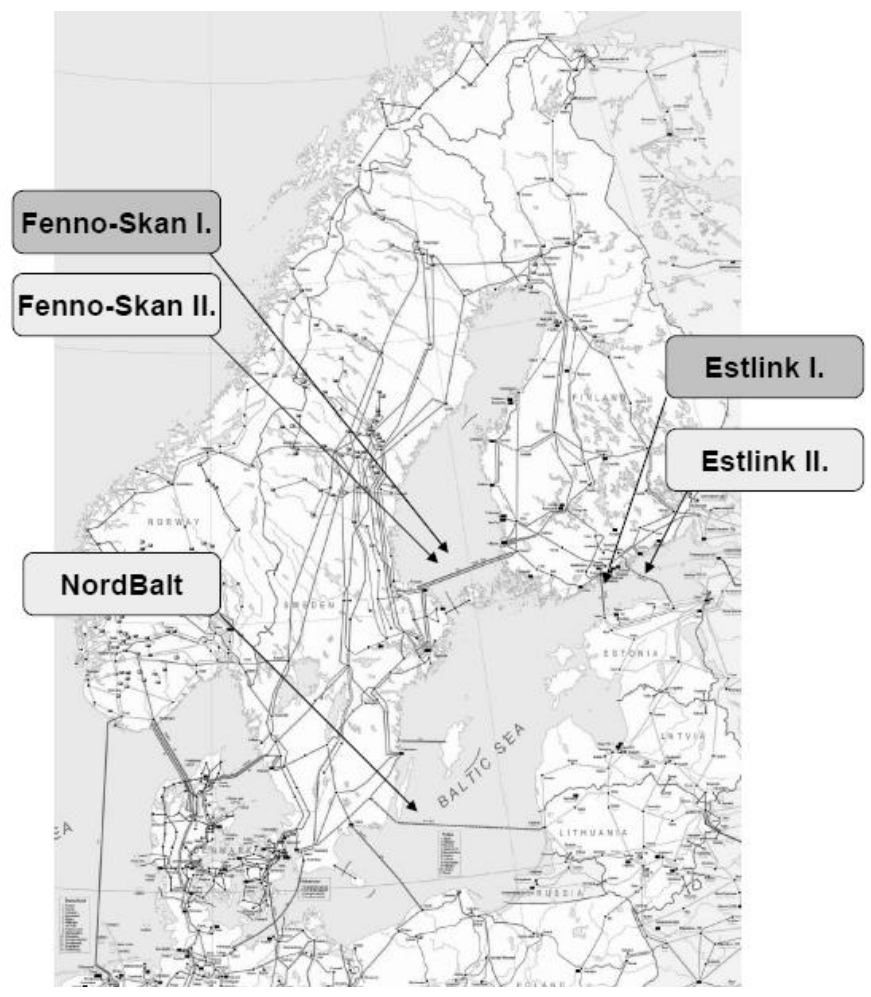

Fig. 5. HVDC interconnections

\section{BALTPOOL AND NORD POOL SPOT}

BaltPool is established in order to foster the creation of harmonized common Baltic electricity market integrated with the Nordic market and further - with Central and Eastern European markets as defined in the Baltic Energy Market Interconnection Plan [4].

The trade is carried out on a day-ahead basis: all electricity delivery agreements are arranged day-ahead for each hour of the following day.

Presently, Nord Pool Spot runs largest international electricity market on the World. Providing services for dayahead market (Elspot) and intra-day market (Elbas) spot trading with physical electricity. As a result of matching supply and demand bids at the spot market, final spot price and trading volumes are determined. Due to potential limitations in transmission capacity spot market in Nordic was divided into Nord Pool spot bidding areas. See Fig. 6.

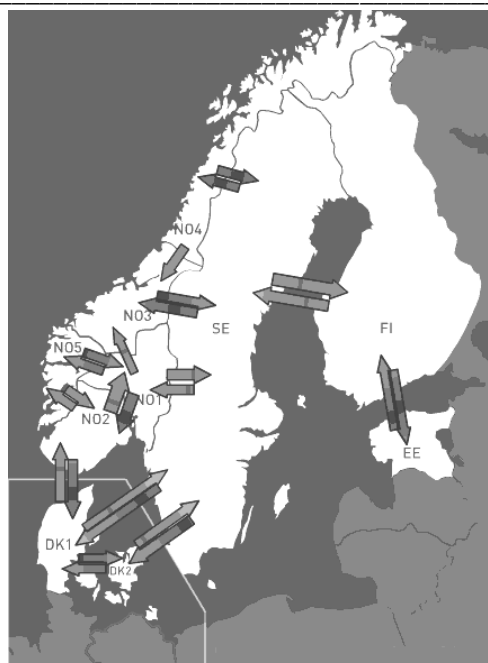

Fig. 6. Nord Pool Spot Areas

Except Denmark and Norway which are subdivided into several spot price areas, boundaries are identical with national borders.

TSOs allocate available transmission capacity on a base of production and consumption forecast. Subsequently, available capacity is allocated at Nord Pool spot market for trading purposes. Allocation of available transmission capacity is done before Nord Pool spot pricing. The available capacities for transmission are reported to Nord Pool pre bidding and are taken into account when price calculation is performed. When no congestion appeared, the prices in different areas are the same (Area price $=$ System price). Market splitting is used if there is congestion. Solving tasks with structural congestion is related to grid investments in case that it is socio-economically feasible, otherwise market splitting is utilized, i.e. dividing the market into separate price areas. Adequate transmission capacity with effective utilization is therefore one of the basic requirements to achieve well functioning and effective electricity market.

Price differences between areas after utilization of transmission capacity between them generate an ownerless income on the spot market, trading flow from the area with a lower price to the area with a higher price. In situations when flow goes from high price area to low price area (towards low price area) due to specific operations or dispatch optimization by TSOs, generating of ownerless costs occurred [2].

These ownerless costs and incomes are referred as congestion rent. Within the Nordic region this income is allocated to the TSOs as owners of the transmission grid. Calculation of congestion rent as follows:

$$
\left(c_{B}-c_{A}\right) P_{A \mapsto B}=C_{R},
$$

where: $c_{A}$ - area price in area A, m.u./MWh;

$c_{B}$ - area price in area $\mathrm{B}$, m.u./MWh;

$P_{A \mapsto B}$ - planned Elspot flow in specific hour from area A to area $\mathrm{B}, \mathrm{MW}$;

$C_{R}$ - aggregated congestion rent m.u. 
Sharing of congestion rent between TSOs is based on Sharing Agreement which provide two possible sharing options. First, calculates adequate share (participation) of all TSOs on Five prioritized projects within Nordel related to Nordic grid development. Second divide congestion rent in two equal shares only between affected TSOs [1]. Incomes of TSOs are commonly used for reduction of tariffs or investments to transmission grid. New Estlink bidding area at Nord Pool Spot was launched on 1 April 2010 and connects Estonia to Nordic electricity market. The long term goal is to create a Baltic market connected to the Nordic market through Nord Pool Spot [5]. The Estlink cable is operated by company AS Nordic Energy Link (NEL). NEL was founded by Baltic and Finnish companies. These share NEL Company (transmission capacity on Estlink) as follows: Baltic companies Eesti Energia (39.9\%), Latvenergo (25\%) and Lietuvos Energija (25\%) and Finnish companies Pohjolan Voima and Helsingin Energia (Finestlink) remaining $10.1 \%$. Shareholders will sell before 2013 entire NEL company to TSOs Fingrid (Finland) and Elering (Estonia) [6].

Suitable environment for Estonian market establishment by Nord Pool Spot arised after Latvenergo and Eesti Energia offered their shares of Estlink capacity to the Estonian and Finnish transmission system operators Elering and Fingrid. This step ensured sufficient capacity for opening the Estlink bidding area.

Available transmission capacity allocated for the Elspotmarket was 252 MW from Finland to Estonia and 262 MW from Estonia to Finland. Since September 2010 TSOs of Finland and Estonia rented full cable capacity from owners and offered for market purposes. After new agreement the available transmission capacity is $350 \mathrm{MW}$ in both directions. See Fig. 7.

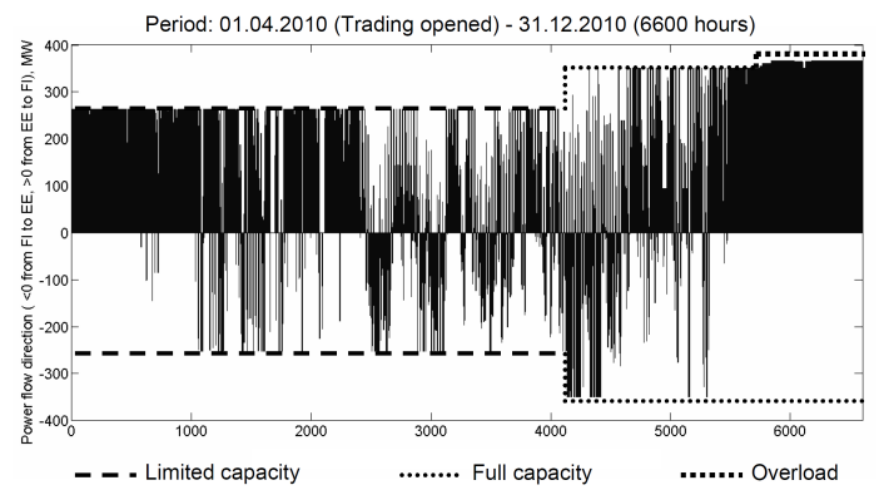

Fig. 7. Estlink power flow utilization by Elspot, 2010

Increasing of transmission capacity through Estlink is very positive for the market development in the Baltic and Nordic. Adequacy capacity is one an important step in markets integration and further on, towards common European market with electricity.

\section{V.LOSSES OPTIMIZATION MANAGEMENT}

For the analysis of Fenno-Scan in the Nordic countries the modified Nordic32-bus test system is used. Its close resemblance to a real power system in Sweden where more generation units are in the north and heavy load centres in the south. The scheme consists of 33 buses, 28 synchronous generators, 51 branches, 3 DC lines and a total of 25 loads. See Fig. 8. As a starting point the simplified single diagram of the CIGRE Nordic32-bus test system [7].

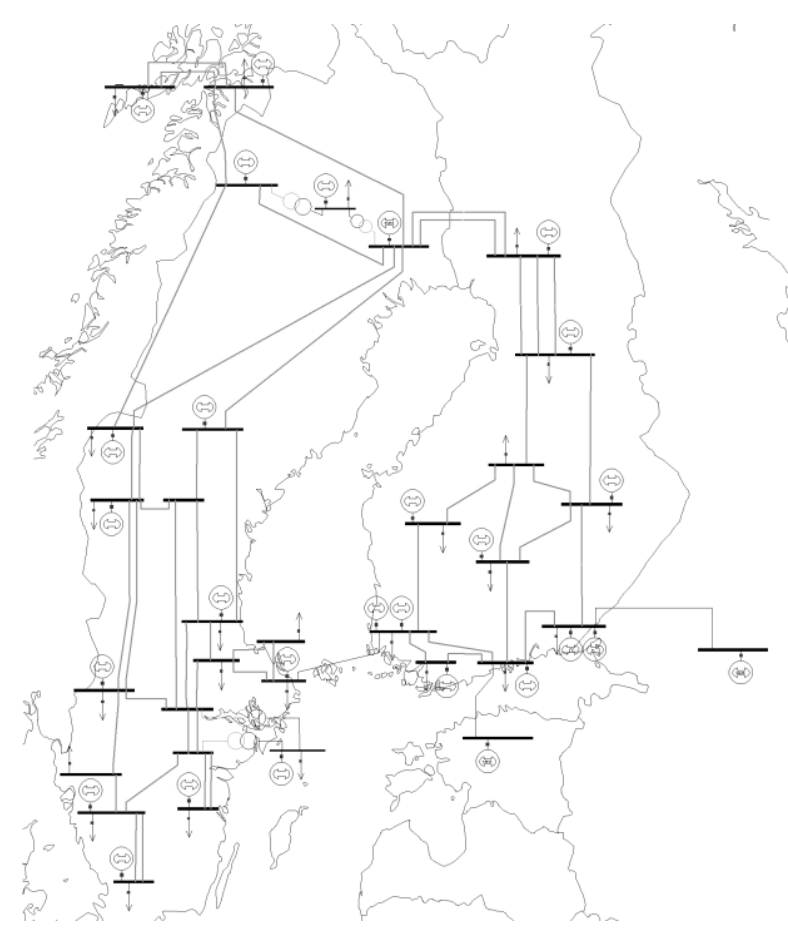

Fig. 8. Scheme of Nordic grid

Model of Nordic grid was created in PowerWorld Simulator which is designed to simulate high voltage power system operation. Software contains power flow analysis and losses calculation. Simulation and parameters of grid elements takes into account current state of real power system in Nordic.

\section{A. Fenno-Skan loss minimization and benefits sharing}

Loss minimization in Finnish and Swedish grids by FennoSkan aggregates benefits which are divided equally between TSOs. Benefits calculation as well as distribution between parties (Fingrid \& SvK) is based on following principles [1]: The overall benefit to the system in particular hour is defined as the positive difference between the calculated overall loss overheads during basic distribution and during the real reference value. As reference value minimal point is usually used. See Fig. 9.

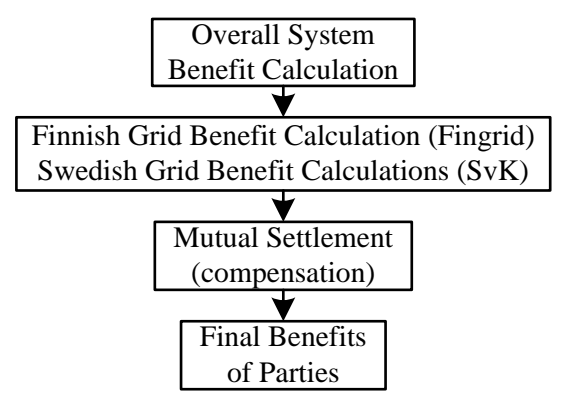

Fig. 9. Fenno-Skan benefit evaluation and distribution 


\section{B. Estlink I losses calculation}

Estlink power flow analysis estimates markets activity and price differences of interconnected areas. Calculations are based on physical power flow through Estlink at hourly basis from 1 April 2010 until 9 April 2011.

Figure 10. shows example of price differences between Estonia and Finland which caused a physical power flow through Estlink. In assumed period only flow from Estonia to Finland appeared.

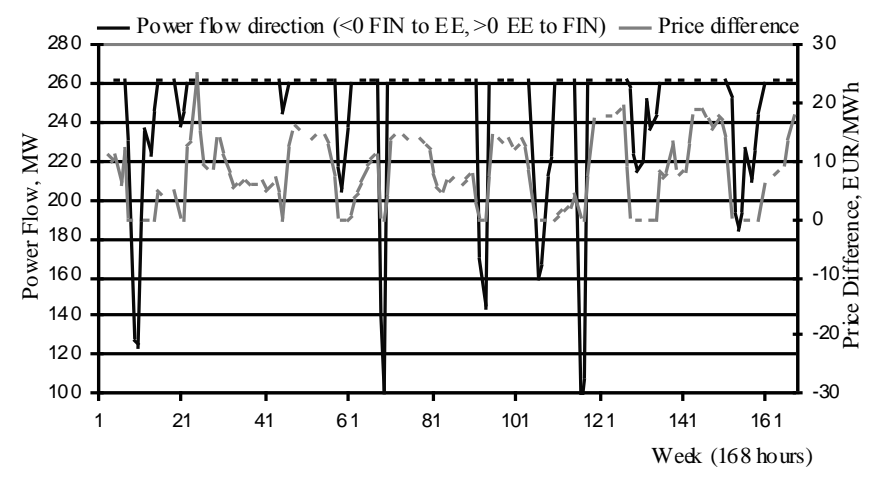

Fig. 10. Price difference \& Estlink power flow

Transmitted volume in assumed period represents 2,295 TWh of which from FI to EE is 0,247 TWh and EE to FI is 2,048 TWh. Calculation of Estlink losses were performed by Estlink Losses Formula. Total calculated losses caused by power flow in both directions are 113,424 GWh of which from FI to EE is $12,807 \mathrm{GWh}$ and EE to FI is $100,617 \mathrm{GWh}$. Value of Ignored transmission losses calculated in compliance with method below for assumed time period is 79766 EUR. This financial loss is borne by owners of interconnection, respectively is transferred to the electricity tariffs and borne by final consumers.

Figure 11 shows one week period Estlink power flow and caused (calculated) power losses.

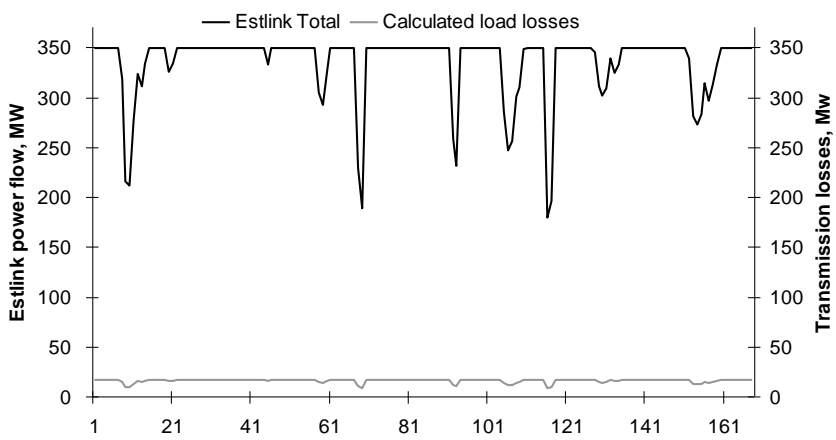

Fig. 11. Physical Estlink power flow \& calculated losses

\section{Ignored transmission losses calculation method}

Term Ignored transmission losses represent part of total transmission losses which are caused in periods (hours) when flow driven by market principles along lines between Areas in comparison to costs of transmission are not economically effective. Social gain from transmitted energy is lower then costs of transmission.
In accordance with principles of electricity market, electricity is purchased from area with lower price and delivered into area with higher price utilizing an available transmission capacity. For profit of such transmission is necessary observe following inequality (show in Fig. 12. and Fig. 13.):

$$
P_{1} \cdot c_{1}<P_{2} \cdot c_{2}
$$

where: $\mathrm{P}_{1}-$ input power flow into transmission line in specific hour, MW;

$\mathrm{P}_{2}$ - power flow in specific hour at the end of line, MW;

$\mathrm{c}_{1}$ - lower area prices EUR/MWh;

$\mathrm{c}_{2}-$ higher area prices EUR/MWh.

Taking into account the losses in the line $\Delta \mathrm{P}=\mathrm{P}_{1}-\mathrm{P}_{2}$ inequality takes the form:

$$
\frac{\Delta P \cdot c_{1}}{P_{2}}<\left(c_{2}-c_{1}\right)
$$

where: $\frac{\Delta P \cdot c_{1}}{P_{2}}=c_{V A R}-$ variable transmission costs, EUR/MWh;

$c_{2}-c_{1}=\Delta c-$ price difference, EUR/MWh.

Transmission of power along the line during periods when formula (3) is in force represents economically effective operation.

$$
0<\Delta c<c_{V A R}
$$

In case that price difference between Areas is under value of variable transmission costs, with respect of limitation (4), aggregation of ignored transmission costs occurred.

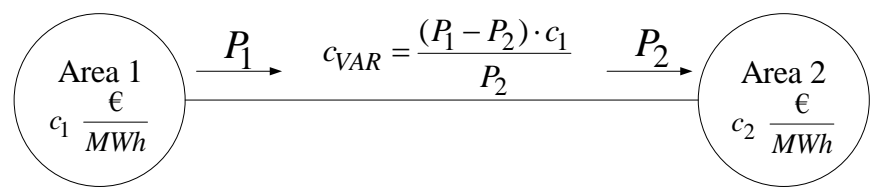

Fig. 12. Example for variable transmission costs calculation

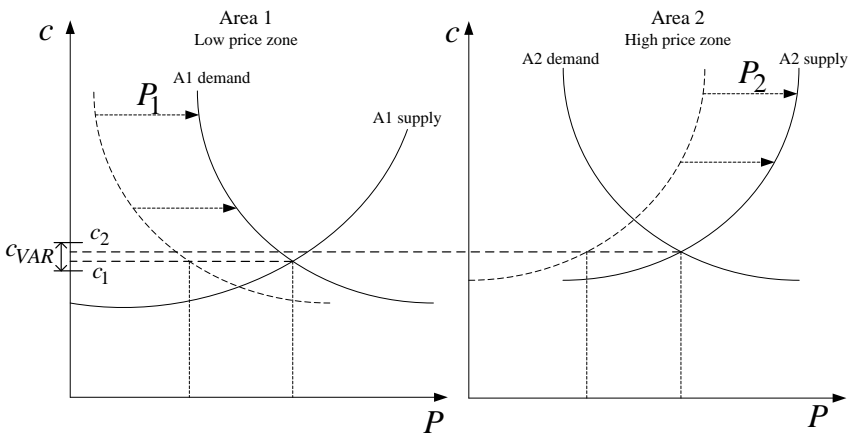

Fig. 13. Demand and supply curves with interconnection for 2 areas

After variable transmission costs $c_{V A R}$ of interconnection were calculated, in compliance with price differences between 
Areas on hourly basis, costs of Ignored transmission losses was obtained as follows:

$$
\text { if } 0<\Delta c<c_{V A R} \text { then } C_{\text {ignored }}=\left(c_{V A R}-\Delta c\right) \cdot P_{2} \text {. }
$$

Considering the connection Estlink I the following example for the 6th December from 8:00 till 9:00 AM is depicted in figure 14 .

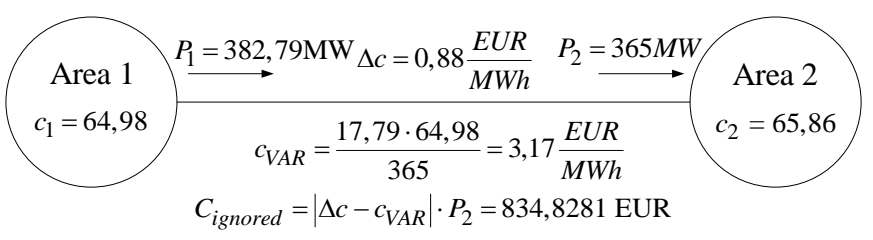

Fig. 14. Example for costs of Ignored transmission losses calculation

This example shows situation when during one particular hour was transmitted in inefficient mode 365 MWh. The transmission, taking into account calculation of ignored transmission losses aggregates financial loss 834,83 EUR.

\section{CONCLUSIONS}

Liberalization of electricity market has bought increased utilization of interconnectors as the importance of cross-border trade increase, as well as has changed character and main purpose of usage. When defining power flow between different price areas based on market principles, TSOs mostly ignore transmission costs that results in inefficient utilization of transmission grid and therefore causes loss to society.

Considering transmission losses when calculating area prices and power flow between price areas seems simple from algorithm point of view. But, it should be further investigated how practically easy it is to change current practices of calculating area price and power flows between price areas by power exchanges to improve economical efficiency of system operation.

\section{REFERENCES}

[1] Nordic Grid Code (Nordic collection of rules), [Online]. Available: https://www.entsoe.eu/fileadmin/user_upload/_library/publications/nordi -c/planning/070115_entsoe_nordic_NordicGridCode.pdf

[2] Nord Pool Spot Report, TSO Congestion rent, [Online]. Available: http://www.nordpoolspot.com/en/reports/Bottleneck-income.

[3] Multiregional planning project "Market based analysis of interconnections between Nordic, Baltic and Poland areas in 2025", from 10 February 2009, [Online]. Available: http://www.fingrid.fi/attachments/sahkomarkkinat/reports/multiregional_planning_project_mar ket_based_analysis_final_v2.pdf

[4] Final Report of the High Level Group: Baltic Energy Market Interconnection Plan, [Online]. Available: http://ec.europa.eu/energy/infrastructure/events/doc/2009/2009_11_25_hlg_report_170609.pdf

[5] Nord Pool Spot - Exchange Information, [Online]. Available: http://www.nordpoolspot.com/en/Market_Information/Exchange-informatio-n/No-242010-NPS--Estonian-market-successfully-opened-during-easter

[6] Nordic Energy Link "Baltic-Finnish submarine cable", Official information [Online]. Available: http://www.nordicenergylink.com/index.php?id=29

[7] Final report CIGRE TF 38.02.08, "Long term dynamics, phase II, ," CE/SC 38.WG02, Ref. no 102, Tech. Rep., 1995.

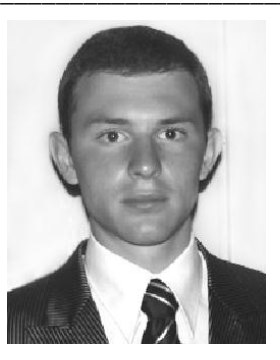

Artjoms Obushevs was born in Riga, Latvia on November 7, 1986. He is received his BSc, MSc degree from the Riga Technical University, in 2008 and 2010 respectively. Currently he is $\mathrm{PhD}$ student in RTU. He is research assistant in the Laboratory of Power System Mathematical Simulation at the Institute of Physical Energetics. His main research interest is Methods of Mathematical Modeling of Electrical Networks and Systems.

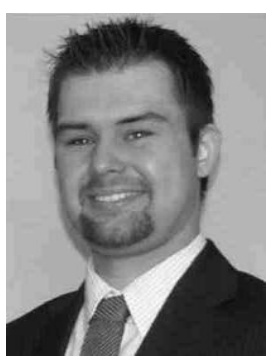

Mario Turcik was born in Humenne, Slovakia on July 16, 1985. He received his Bachelor and Master degree from the Technical University of Kosice, in 2008, 2010. Currently PhD student Technical University of Kosice and Assistant in Laboratory of Electric Power System Simulation at the Institute of Physical Energetics in Riga. His research interests include Methods for Development of Power Systems Planning and Electricity Market.

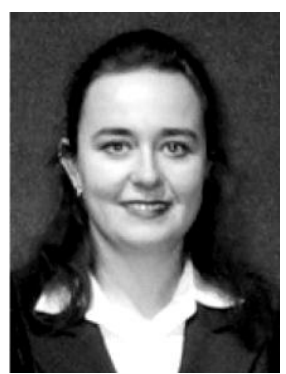

Irina Oleinikova was born in Riga, Latvia, on September 16, 1974. She received the BSc, E.E., MSc and Dr.sc.ing. degrees from the Riga Technical University, in 1994, 1995, 1997 and 2000 respectively. She is senior researcher in the Laboratory of Power Systems Mathematical Modelling at the Institute of Physical Energetics. Her main research interests include Methods for Mathematical Modelling of Electrical Networks and Systems; Methods for Development of Power systems Planning; Dynamic Optimization Methods and Decision Systems. She is author more then 100 papers,including 4 books.

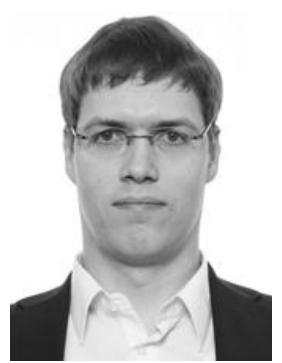

Gatis Junghans was born in Latvia, 1979. He has 10 year professional experience in power industry. He had worked in power distribution and transmission companies and since 2005 his professional field is power trading. He received Dr.sc.ing. from the Riga Technical University in 2008 and MBA degree from Stockholm School of Economics in Riga in 2010. 